\title{
Effect of Partial Replacement of Hydroxypropyl Methylcellulose Nanofibers of Portland Cement on the Corrosion Behavior of Reinforced Concrete Structures
}

\author{
Bing $\mathrm{Gao}^{1,{ }^{*}, \text { Jiannan Tong }}{ }^{2, *}$, Xujing $\mathrm{Ni}^{3,2}$, Songying $\mathrm{Guo}^{2}$, Yonghua Wang $^{2}$ \\ ${ }^{1}$ School of Civil Engineer,Jilin Jianzhu University, Changchun 130118,Jilin Province,China. \\ ${ }^{2}$ Department of Civil Engineering, Tangshan University, Tangshan 063000, China \\ ${ }^{3}$ State Key Laboratory of Hydroscience and Engineering, Tsinghua University, Beijing 100084, China \\ *E-mail: gb0431@126.com and tongjiannan126@ sina.com
}

doi: $10.20964 / 2020.08 .35$

Received: 12 March 2020/ Accepted: 9 May 2020 / Published: 10 July 2020

\begin{abstract}
Nowadays, steel reinforced concretes have been widely used as a building material. However, building materials are usually exposed to corrosive environments which frequently leads to the corrosion of steel rebar. In this work, the effect of hydroxypropyl methylcellulose nanofibers (HMFs) as a partial replacement in Portland cement on corrosion behavior of mild steel rebar were studied in $3.5 \mathrm{wt} \%$ $\mathrm{NaCl}$ solution. Electrochemical impedance spectroscopy analysis, polarization measurement and permeability test were used to investigate the corrosion behavior of mild steel rebar. The lower permeability of the concrete was directly related to the increase in HMFs concentration which had led to the production of denser concrete. The electrochemical results revealed that the sample with $2 \mathrm{~kg} / \mathrm{m}^{3}$ HMFs had higher corrosion potential and resistance than all the others. Moreover, the resistance of passive layer increased in the reinforced concrete sample with $2 \mathrm{~kg} / \mathrm{m}^{3} \mathrm{HMFs}$, which revealed that the protective property of the passive layer developed was strong. These findings revealed that partial replacement of HMFs in Portland cement caused a reduction of corrosion rate and increased corrosion resistance of mild steel rebar because of the decrease of chloride ion and water permeability.
\end{abstract}

Keywords: Hydroxypropyl methylcellulose nanofibers;Partial replacement;Corrosion behavior;Reinforced concrete; Electrochemical analysis

\section{FULL TEXT}

(C) 2020 The Authors. Published by ESG (www.electrochemsci.org). This article is an open access article distributed under the terms and conditions of the Creative Commons Attribution license (http://creativecommons.org/licenses/by/4.0/). 